\title{
Comparison between FAC Analysis Result Using ToSPACE \& CHECWORKS Programs and Experimental Result
}

\author{
K. M. Hwang1, H. Yun1, H. K. Seo', E. J. Jung1, J. S. Im¹, K. M. Kim², D. J. Kim² \\ ${ }^{1}$ PSA \& PSR Business Department, Gimcheon-si, Korea \\ ${ }^{2}$ Materials Safety Technology Development Division, Daejeon-si, Korea \\ Email: hkm@kepco-enc.com
}

How to cite this paper: Hwang, K.M., Yun, H., Seo, H.K., Jung, E.J., Im, J.S., Kim, K.M. and Kim, D.J. (2020) Comparison between FAC Analysis Result Using ToSPACE \& CHECWORKS Programs and Experimental Result. World Journal of Nuclear Science and Technology, 10, 158-170. https://doi.org/10.4236/wjnst.2020.104014

Received: September 10, 2020

Accepted: October 12, 2020

Published: October 15, 2020

Copyright $\odot 2020$ by author(s) and Scientific Research Publishing Inc. This work is licensed under the Creative Commons Attribution International License (CC BY 4.0).

http://creativecommons.org/licenses/by/4.0/

\begin{abstract}
A number of piping components in the secondary system of nuclear power plants (NPPs) have been exposed to aging mechanisms such as FAC (FlowAccelerated Corrosion), cavitation, flashing, LDIE (Liquid Droplet Impingement Erosion), and SPE (Solid Particle Erosion). Those mechanisms may lead to thinning, leaking, or the rupture of components. Due to the pipe ruptures caused by wall thinning of Surry Unit 2 in 1986 and Mihama Unit 3 in 2004, pipe wall thinning management has emerged as one of the most important issues in the nuclear industry. To manage the wall thinning of pipes caused by FAC and erosion, KEPCO-E \& C has developed ToSPACE program. It can predict both FAC \& erosion phenomena, and also be utilized in the pipe wall thinning management works such as susceptibility analysis, UT (Ultrasonic Test) data evaluation as well as establishment of long-term inspection plan. Even though the ToSPACE can predict the five aging mechanisms mentioned above, only the FAC prediction result using ToSPACE was compared herein with the experimental result using FACTS (Flow Accelerated Corrosion Test System) to verify the ToSPACE's capability. In addition, the FAC prediction result using ToSPACE was also compared with that of CHECWORKS that is widely used all over the world.
\end{abstract}

\section{Keywords}

ToSPACE, FACTS (Flow Accelerated Corrosion Test System), Pipe Wall Thinning, Flow-Accelerated Corrosion (FAC)

\section{Introduction}

The secondary side piping of nuclear power plants has experienced wall thinning 
phenomenon in which the pipes gradually become thinner as the number of operating years increases because of fluid flowing at high-temperature, high-pressure and high-velocity. Aging mechanisms that cause the wall thinning of the secondary side piping in nuclear power plants include FAC, LDIE, Cavitation, Flashing, and SPE [1].

If the piping is leaked or ruptured due to wall thinning, it may experience the damage of workers as well as economic loss. Such examples include the pipe ruptures of Surry Unit 2 in 1986 [2] and Mihama Unit 3 in 2004 [3]. The pipe wall thinning continues to occur at nuclear power plants and it is expected to increase gradually as the number of operating year increases. In order to manage the wall thinning of pipes, CHECWORKS program has been used in the United States, BRT-CICERO in France, and COMSY in Germany.

To manage the wall thinning of pipes in the secondary system, Korea has used an overseas program since 1996. As using the foreign country's program for long period of time, it has become necessary to reflect our experiences and lessons learned so as to improve the existing foreign program from the demands of the users. Accordingly, KEPCO-E \& C has developed our owned 3D-based pipe wall thinning management program (ToSPACE, Total Solution for Piping And Component Engineering management). ToSPACE includes the ability to predict the wall thinning caused by FAC, LDIE, Cavitation, Flashing, and SPE at once. In addition, it includes the capabilities of sensitivity analysis, 3D DB construction, inspection data reliability analysis, UT data evaluation, and long-term inspection plans which are utilized for the pipe wall thinning management works at plant site [4].

In this paper, the predicted results by ToSPACE and the experimental results by FACTS facility were compared for FAC which is the typical aging mechanism that occurs in the secondary side piping of nuclear power plants. FACTS was developed by KAERI (Korea Atomic Energy Research Institute) for FAC tests [5] [6]. In addition, the FAC prediction results using the ToSPACE were also compared with those of the CHECWORKS program.

\section{Experiment}

\subsection{Experimental Approach}

The secondary system of nuclear power plants consists of a closed loop for generating electricity. Since high-temperature, high-pressure \& high-velocity fluid flows inside carbon steel piping responsible for the transport of water and steam on the secondary system, the thickness of the pipes may gradually become thinner if used for long period of time. The FAC analysis results using the ToSPACE were compared with the results of the experiment using FACTS experimental facility to verify the prediction results.

FACTS is a test facility that can demonstrate and simulate the phenomenon of FAC, and it can observe the thickness change of piping by connecting test pipes to a loop that circulates high-temperature, high-pressure, and high-velocity fluid 
[5]. In addition, the ion exchange water purification system is installed in the water extraction line, while the water chemistry control system is installed in the water injection line to regulate the dissolved oxygen concentration, conductivity, $\mathrm{pH}$, etc. of the test fluid.

Figure 1 shows the overall shape of the FACTS experimental facility, whereas Figure 2 depicts only the parts to observe the thickness change of the pipe. Figure 3 is an installation design drawing. High-velocity circulation piping (shaded part) is a $101.6 \mathrm{~mm}$ (4 inches) diameter pipe made of stainless steel (A312 TP304) to prevent corrosion, and the white piping subject to the FAC test is made of carbon steel (A106 B) being widely used as piping materials on the secondary side of nuclear power plants. The piping in the carbon steel section is $50.8 \mathrm{~mm}$ ( 2 inches) schedule 80 , with two orifices and two elbows installed. The inside diameter of the orifice is $40 \mathrm{~mm}$, and the ratio to the diameter of the pipe $(\beta)$ is 0.8 . The material of elbows is also carbon steel with a radius of curvature of 76 $\mathrm{mm}$. Table 1 is a database constructed to compare experiment results with the ToSPACE analysis results. In Component Name, the preceding third alphabet indicates the type of piping component. In other words, $\mathrm{P}$ represents a straight pipe, $\mathrm{E}=$ an elbow, $\mathrm{R}=$ a reducer, $\mathrm{V}=\mathrm{a}$ valve, $\mathrm{O}=$ an orifice, and $\mathrm{X}=$ an expander. The last two digits indicate the order in which they were installed.

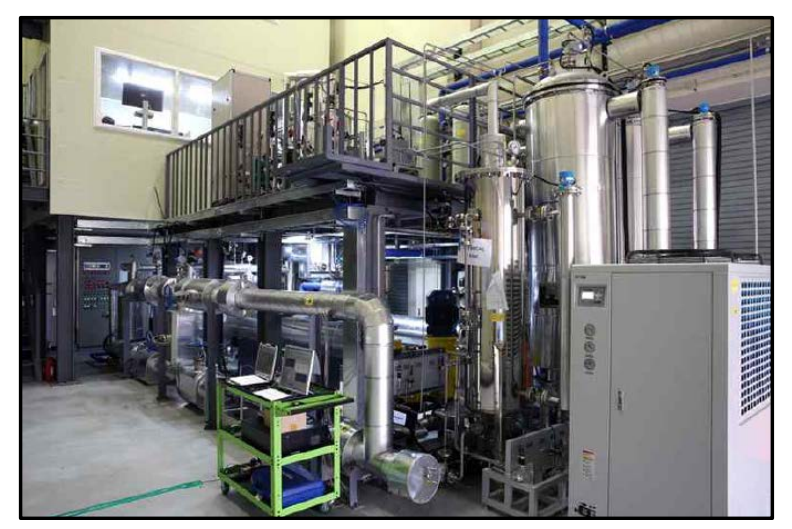

Figure 1. Flow Accelerated Corrosion Testing System (FACTS).

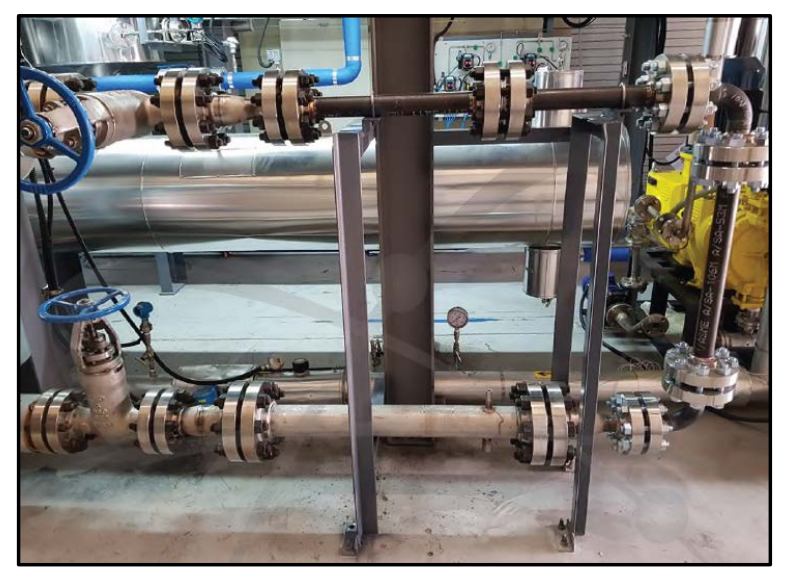

Figure 2. Photograph of experiment parts. 
Table 1. Database of experiment model.

\begin{tabular}{|c|c|c|c|c|c|c|c|c|}
\hline No. & $\begin{array}{l}\text { Component } \\
\text { Name }\end{array}$ & Material & $\mathrm{OD}, \mathrm{mm}$ & Thickness, mm & ID, mm & Length, mm & $\begin{array}{l}\text { Insulation } \\
\text { Type }\end{array}$ & $\begin{array}{c}\text { Insulation } \\
\text { Thickness, mm }\end{array}$ \\
\hline 1 & W-P01 & A312 TP304 & 88.9 & 5.49 & 77.93 & 500 & Calcium Silicate & 55 \\
\hline 2 & W-V01 & A312 TP304 & 88.9 & 5.49 & 77.93 & 500 & Calcium Silicate & 55 \\
\hline 3 & W-R01 & A312 TP304 & $88.9 \times 60.3$ & $5.49 \times 5.54$ & $77.93 \times 49.25$ & 187 & Calcium Silicate & 55 \\
\hline 4 & W-P02 & A106 & 60.3 & 5.54 & 49.25 & 643 & - & - \\
\hline 5 & $\mathrm{~W}-\mathrm{O} 01$ & A106 & 60.3 & - & 40 & 5 & - & - \\
\hline 6 & W-P03 & A106 & 60.3 & 5.54 & 49.25 & 580 & - & - \\
\hline 7 & W-E01 & A106 & 60.3 & 5.54 & 49.25 & - & - & - \\
\hline 8 & W-P04 & A106 & 60.3 & 5.54 & 49.25 & 839 & - & - \\
\hline 9 & W-O02 & A106 & 60.3 & - & 40 & 5 & - & - \\
\hline 10 & W-P05 & A106 & 60.3 & 5.54 & 49.25 & 218 & - & - \\
\hline 11 & W-E02 & A106 & 60.3 & 5.54 & 49.25 & - & - & - \\
\hline 12 & W-P06 & A106 & 60.3 & 5.54 & 49.25 & 155 & - & - \\
\hline 13 & W-X01 & A312 TP304 & $60.3 \times 114.3$ & $5.54 \times 6.02$ & $49.25 \times 102.26$ & 217 & Calcium Silicate & 55 \\
\hline 14 & W-P07 & A312 TP304 & 114.3 & 6.02 & 102.26 & 500 & Calcium Silicate & 55 \\
\hline
\end{tabular}

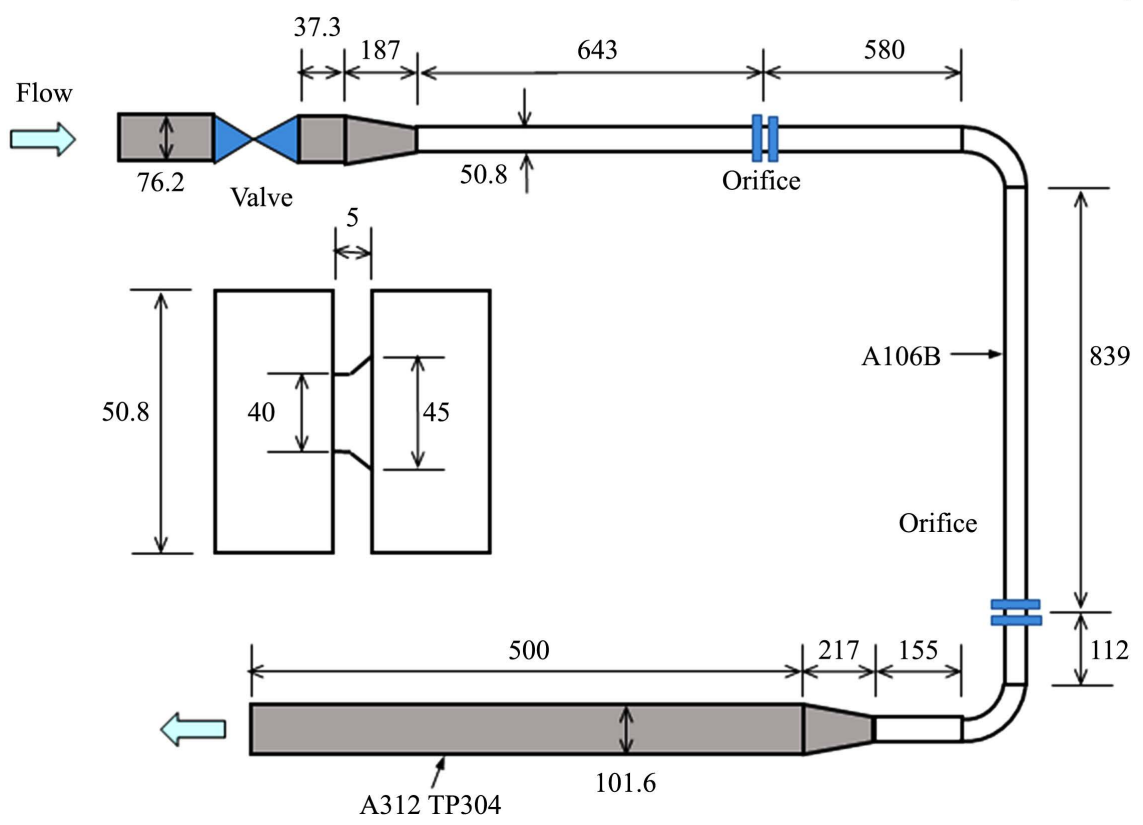

Figure 3. Design of experiment parts.

\subsection{Experimental Results}

The hot water discharged from the $88.9 \mathrm{~mm}$ main circulation loop made of stainless steel is cooled down to room temperature through a heat exchanger, and the water chemistry concentration such as dissolved oxygen (DO), conductivity, and $\mathrm{pH}$ is controlled and recirculated using an ion exchange resin system 
and nitrogen ventilation facility. In order to simulate conditions equivalent to those on the secondary side of nuclear power plants, DO was kept below $5 \mathrm{ppb}$, conductivity below $1 \mu \mathrm{S} / \mathrm{cm}$, and $\mathrm{pH}$ at around 8 during the experiment. The change in pipe thickness was measured by Ultrasonic Testing (UT) before and after the experiment to observe the change in thickness during the experiment period. For UT measurements, the inspecting grids were drawn, and the thickness differences before and after the experiment were observed at the same locations. The experimental conditions for verifying the ToSPACE were $130^{\circ} \mathrm{C}, \mathrm{pH}$ 8.2 , pressure 8 bars, flow velocity $3 \mathrm{~m} / \mathrm{s}$, and the experiment was carried out for 1220 hours.

As shown in Figure 4, the UT inspections were performed before and after the experiment at the marking points on the surface of four components. W-P03 is the straight pipe downstream of the first orifice (170 inspection points), $\mathrm{W}$-E01 is the first elbow (100 inspection points), W-P04 is the vertical pipe between the first elbow and the second orifice (150 inspection points), and W-E02 is the second elbow (100 inspection points). The average, minimum and maximum wall thinning rates for each component are as shown in Table 2. Among the four components, W-E02 is considered to have the greatest average wear rate, which is believed to have been affected by turbulence generated by combination of the second orifice and elbow. The next is W-E01, which is farther to the orifice than W-E02. The smallest W-P03 is a pipe immediately downstream of the orifice, but it is assumed at some points that the turbulence generated in the orifice was severely affected. It can be seen from the maximum wall thinning rate of $0.7 \mathrm{~mm} / \mathrm{yr}$.

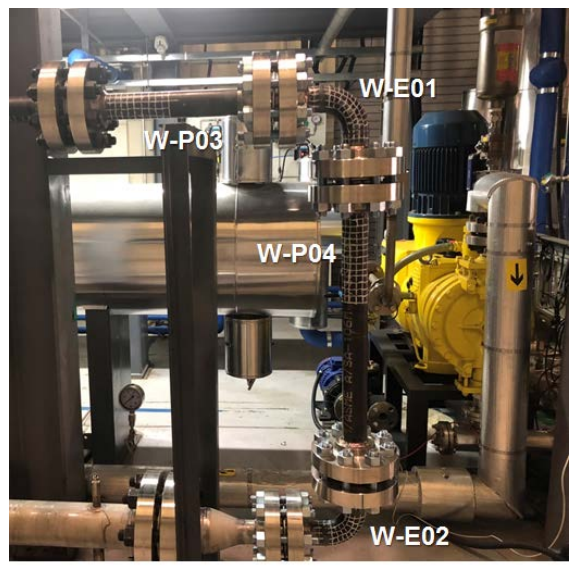

Figure 4. UT measurement regions.

Table 2. Average, min, and max wall thinning rates measured by UT (unit: $\mathrm{mm} / \mathrm{y}$ ).

\begin{tabular}{ccccc}
\hline Component No. & W-P03 & W-E01 & W-P04 & W-E02 \\
\hline Average & 0.27 & 0.43 & 0.38 & 1.19 \\
Minimum & 0.10 & 0.20 & 0.18 & 0.80 \\
Maximum & 0.70 & 0.65 & 0.55 & 1.50 \\
\hline
\end{tabular}




\section{FAC Analysis Using ToSPACE}

\subsection{Construction of Analysis Model}

In order to verify the FAC prediction function of ToSPACE, an analysis model was constructed using Table 1 in the same way as the experimental parts to observe the thickness change of the pipes. Toperform FAC analysis using the ToSPACE, the actual installed piping type must be constructed as a 3D DB. This is to reflect the actual length, pipe size, material, type of component, etc. of the installed piping for the calculation of fluid flow. When using the ToSPACE, DB is automatically constructed by entering the diameter, thickness, material, design pressure, design temperature, and insulation information of pipes at the beginning of 3D construction. This approach can reduce human error to a minimum level because it is created by the user visually checking the piping layout [7]. Figure 5 is a $3 \mathrm{D}$ model of ToSPACE that is identical to the experimental parts. In the figure, the upper left hand side shows the name of the pipe components, and the lower left side shows the piping properties that appear when a pipe component is clicked. The window on the right provides a library related to design information that is utilized when constructing $3 \mathrm{D}$.

\subsection{FAC Analysis}

The wall thinning analysis using the ToSPACE can be conducted by entering

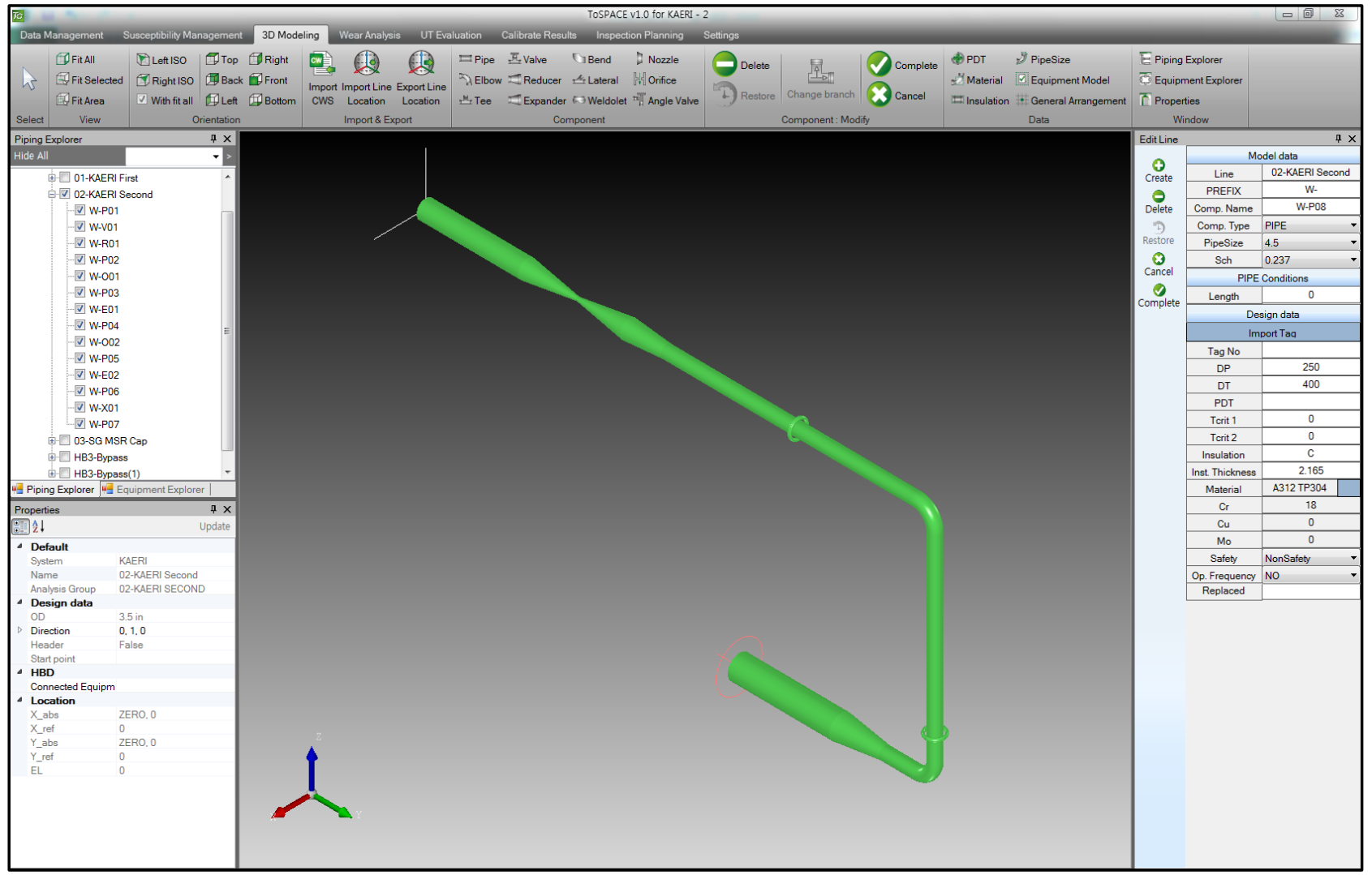

Figure 5. 3D model for ToSPACE analysis. 
boundary conditions, such as pressure, temperature, enthalpy and water chemistry data, as necessary at the pipe inlet and outlet shown in 3D. Here, the wall thinning analysis is a term that encompasses the aging mechanisms, such as FAC, LDIE, SPE, cavitation, etc. Figure 6 shows the setting of boundary conditions entered to perform the wall thinning analysis. The wall thinning analysis of CHECWOKRS is carried out after performing the water chemistry analysis and thermal hydraulic analysis separately, but in ToSPACE, the water chemistry analysis, thermal hydraulic analysis and wall thinning analysis are conducted simultaneously. In addition, if the fluid is two-phase or contains solid particles, LDIE and SPE analyses are also progressed simultaneously with the FAC analysis. Of course, for single-phase fluid condition, cavitation and flashing analyses are also performed simultaneously.

Figure 7 shows the results of the wall thinning analysis for comparison with the results of the experiment with the FACTS experimental facility. Even though it is possible to analyze all the above-mentioned aging mechanisms by means of ToSPACE, the FAC analysis results were just presented because the only FAC experiment was performed at the experimental facility. In Figure 7, the color of the piping indicates the degree of wear rate, where the red color means the greater wear rate and the yellow color means less. The figure shows that the wear rates in the two elbows were calculated to be the largest except for the orifices.

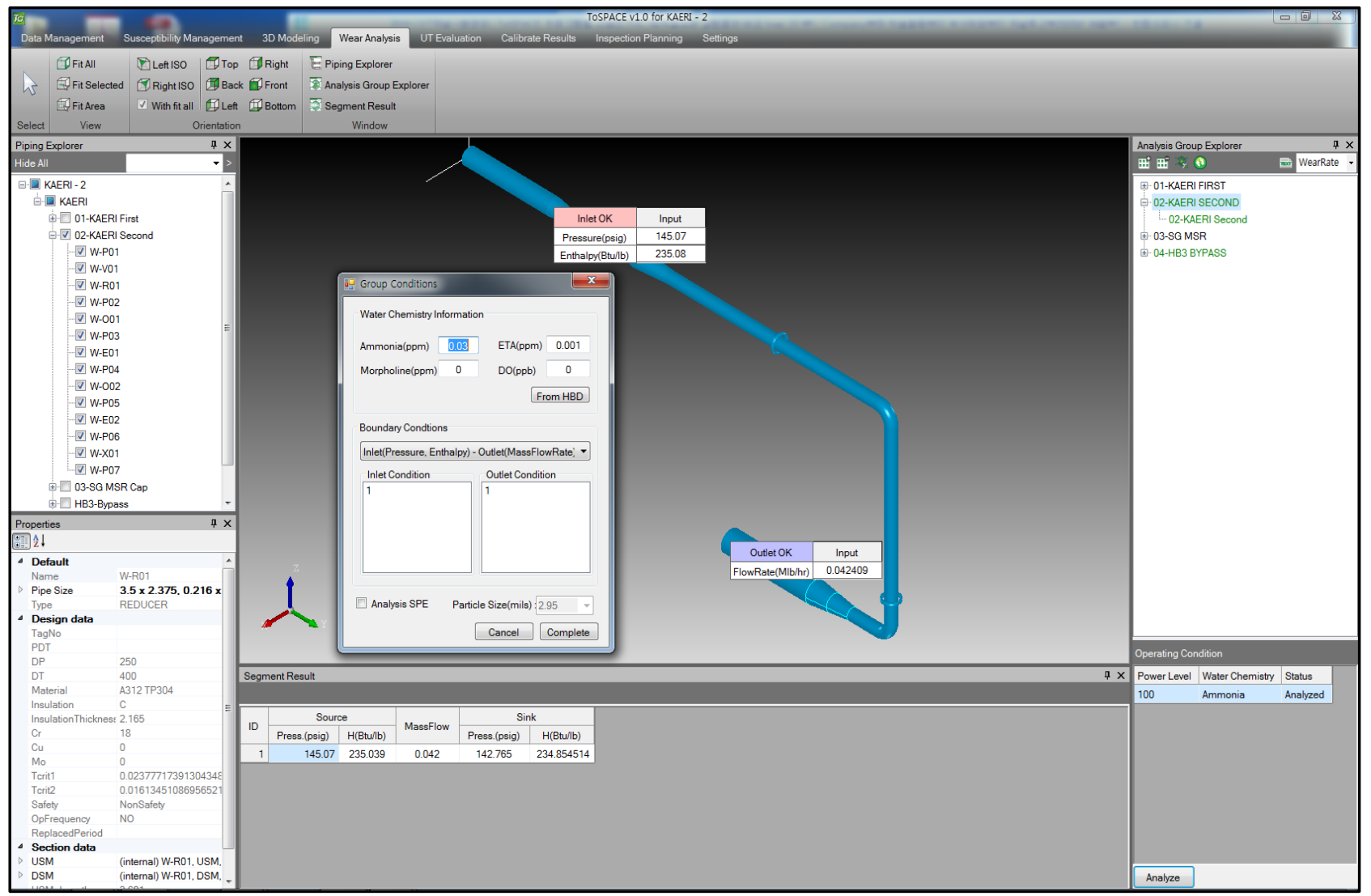

Figure 6. Setting of boundary condition for ToSPACE analysis. 


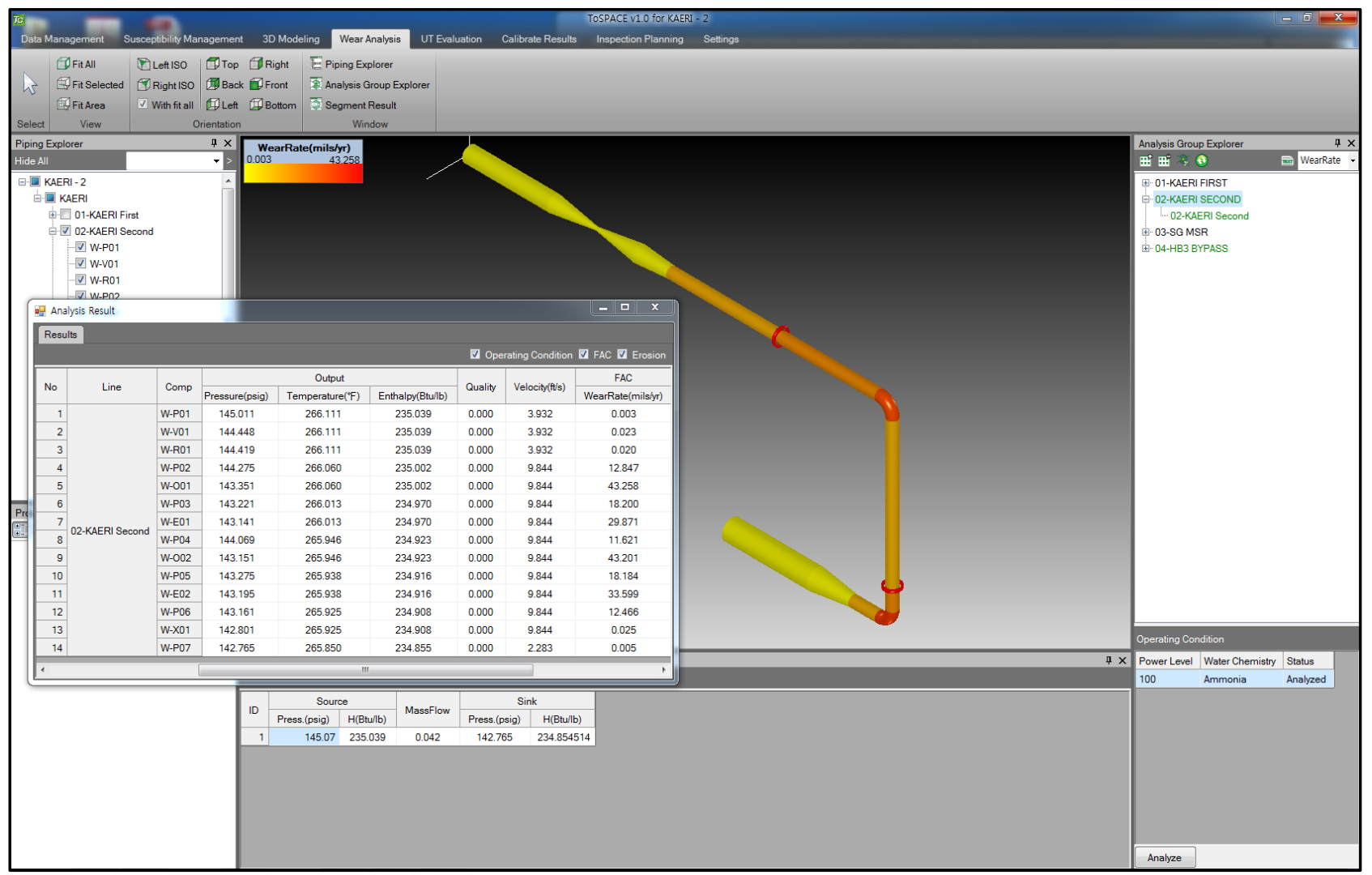

Figure 7. FAC analysis results using ToSPACE.

\section{FAC Analysis Using CHECWORKS}

\subsection{Construction of Analysis Model}

To compare the FAC prediction function of ToSPACE with the CHECWORKS in addition to the experimental results, the analytical model was constructed equally with the CHECWORKS as shown in Figure 8. In order to predict FAC using the CHECWORKS, the DB was first constructed for the piping components and pipe lines as shown in the left-hand screen in Figure 8, and then the piping was constructed with $3 \mathrm{D}$ form using the Component Connectivity function [8]. The method constructing DB and 3D in CHECWORKS is completely opposite to that of ToSPACE.

\subsection{FAC Analysis}

Figure 9 shows the procedure for performing the wall thinning analysis using the CHECWORKS. In order to perform the wall thinning analysis for the pipeline shown in Figure 8, the water chemistry analysis was conducted preferentially with water chemistry data entered in a separated window. Variables calculated here include $\mathrm{pH}$ and amine concentration in the pipeline. Then, the network flow analysis (NFA) was conducted to calculate the thermal hydraulic data (pressure, enthalpy, flow rate, etc.) for all the components composing the pipeline. 


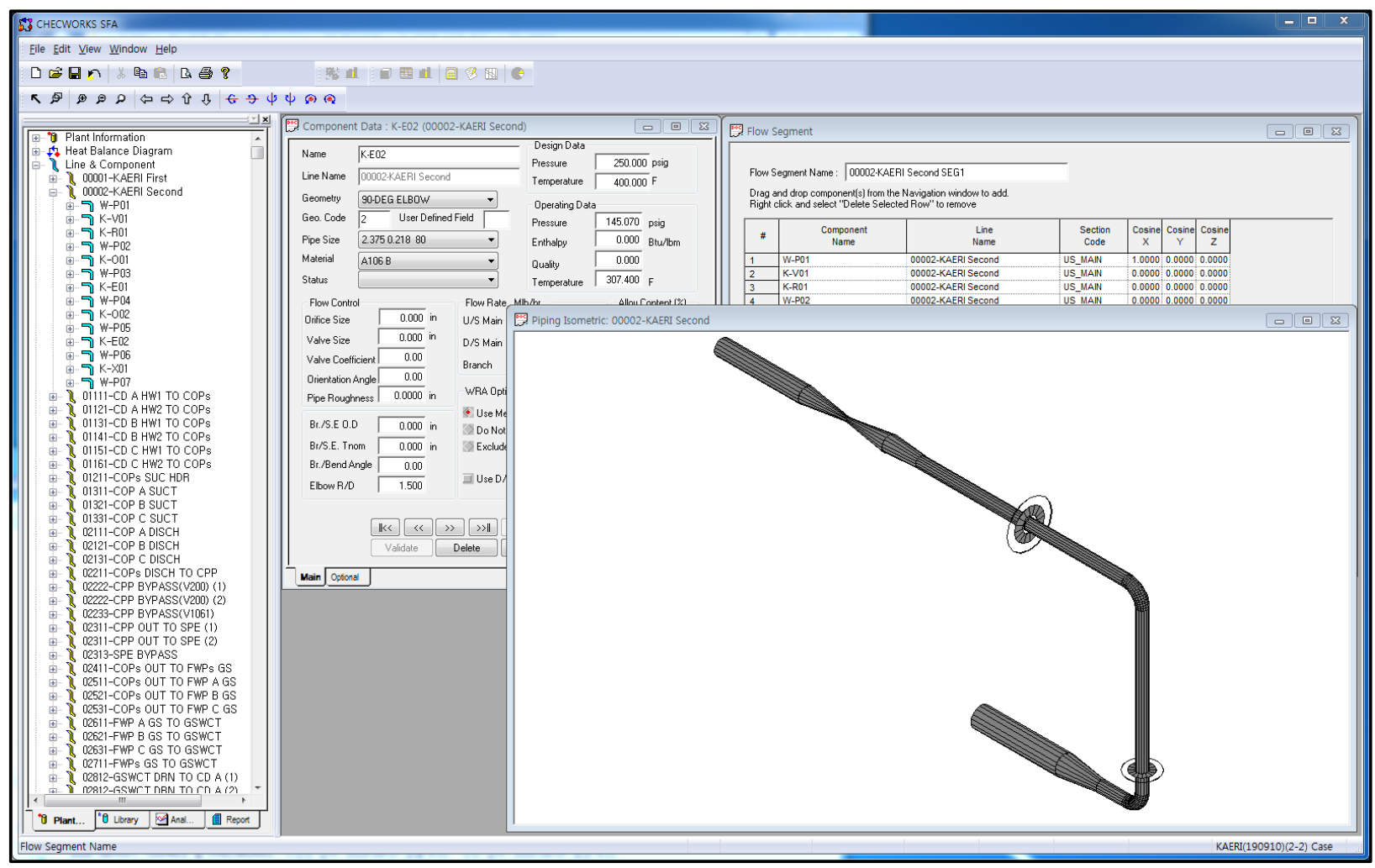

Figure 8. 3D model for CHECWORKS.

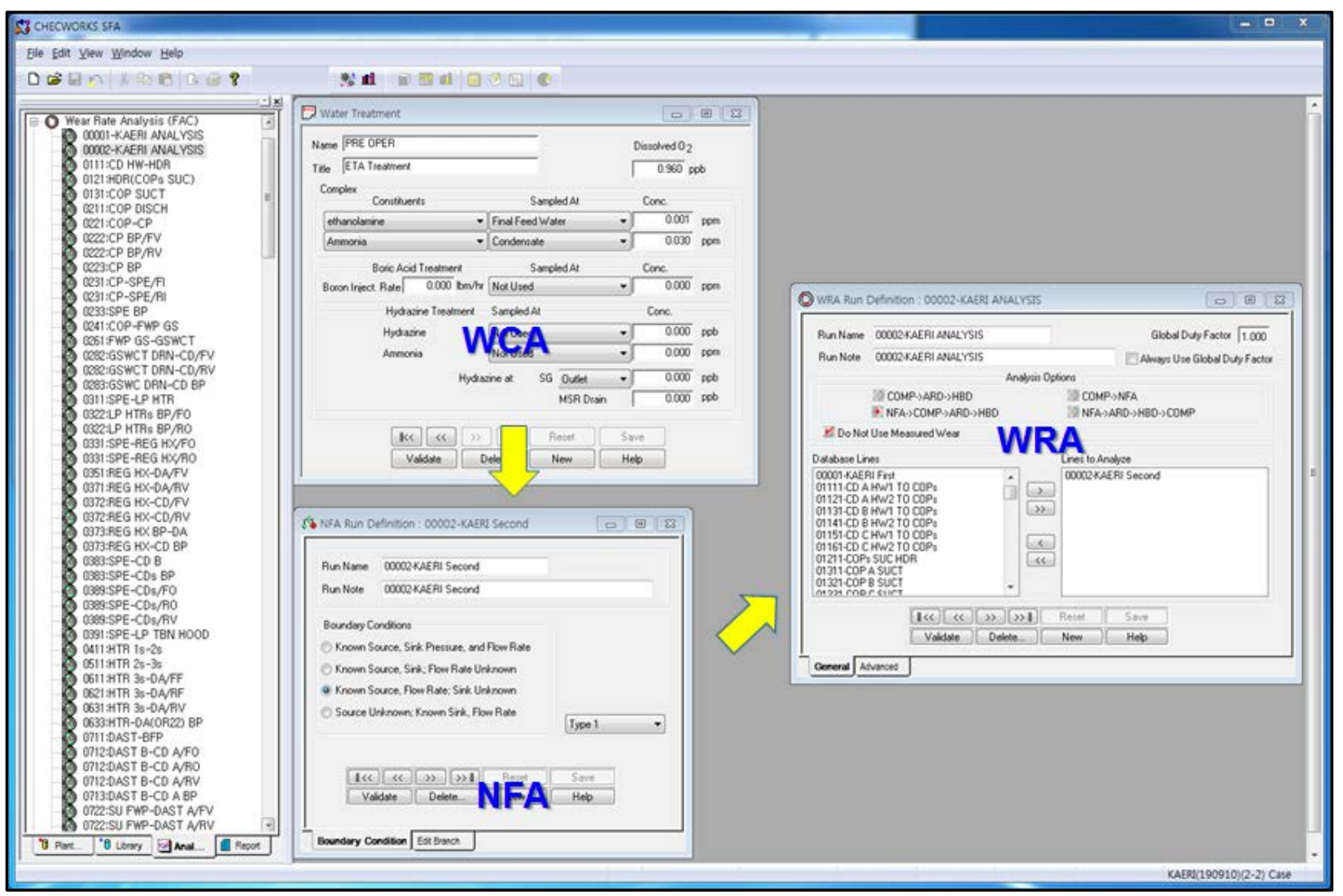

Figure 9. Analysis step of CHECWORKS. 
Finally, the wall thinning analysis using data calculated from water chemistry analysis and network flow analysis was conducted [9]. The wear rates by component were calculated in the wall thinning analysis. Figure 10 shows the wear rate analysis result report calculated with the CHECWORKS. The temperature, flow rate and steam quality shown in the figure are calculated from the network flow analysis, and $\mathrm{pH}$ is calculated from the water chemistry analysis.

\section{Comparison of Experiment and Analysis Results}

The results of the FAC analysis using the ToSPACE and CHECWORKS were compared with the results of the experiments by FACTS experimental facility. The comparison locations are the four areas (W-P03, W-E01, W-P04, W-E02) as shown in Figure 11. Figure 12 compares the experimental results with those of the FAC analysis using ToSPACE and CHECWORKS in the four areas. The bar graph in Figure 12 is the experimental results, the solid line graph is the ToSPACE analysis results, and the dotted line graph is the CHECWORKS analysis

\begin{tabular}{|c|c|c|c|c|c|c|c|c|}
\hline \multicolumn{9}{|c|}{ Wear Rate Analysis: Wear Rate Report } \\
\hline \multicolumn{3}{|c|}{ 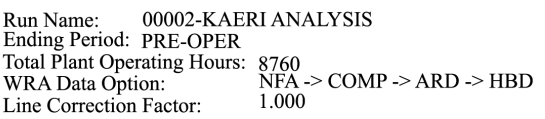 } & \multicolumn{2}{|c|}{$\begin{array}{l}\text { Duty Factor (Global): } \\
\text { Exclude Measure Wear: } \\
\text { Figure of Merit \# (\%): }\end{array}$} & \multicolumn{2}{|l|}{$\begin{array}{l}1.000 \\
\text { YES } \\
0.00\end{array}$} & \multirow[b]{2}{*}{$\begin{array}{l}\text { OD } \\
\text { (in) }\end{array}$} & \multirow[b]{2}{*}{ Hot $\mathrm{pH}$} \\
\hline $\begin{array}{l}\text { Component } \\
\text { Name }\end{array}$ & $\begin{array}{l}\text { Geom } \\
\text { Code }\end{array}$ & $\begin{array}{l}\text { Average } \\
\text { Wear Rate } \\
\text { (mils/yr) }\end{array}$ & $\begin{array}{l}\text { Current } \\
\text { Wear Rate } \\
\text { (mils/yr) }\end{array}$ & $\begin{array}{l}\text { Temp } \\
\text { (F) }\end{array}$ & $\begin{array}{l}\text { Velocity } \\
(\mathrm{ft} / \mathrm{s})\end{array}$ & Quality & & \\
\hline \multicolumn{9}{|c|}{$==>$ Grouped by Line: 00002-KAERI Second, Sorted By: Flow Order } \\
\hline W-P01 & 9 & 0.007 & 0.007 & 266.3 & 3.933 & 0.000 & 3.500 & 5.875 \\
\hline K-V01 & 21 & 0.047 & 0.047 & 266.3 & 3.933 & 0.000 & 3.500 & 5.875 \\
\hline K-R01 & 17 & 0.019 & 0.019 & 266.3 & 9.806 & 0.000 & 3.500 & 5.875 \\
\hline K-R01 (D/S) & 17 & 0.031 & 0.031 & 266.3 & 9.806 & 0.000 & 2.375 & 5.875 \\
\hline W-P02 & 67 & 41.463 & 41.463 & 266.3 & 9.846 & 0.000 & 2.375 & 5.875 \\
\hline $\mathrm{K}-\mathrm{O} 01$ & 6 & 348.468 & 348.468 & 266.3 & 14.923 & 0.000 & 3.500 & 5.875 \\
\hline W-P03 & 56 & $\begin{array}{r}34.400 \\
18.851\end{array}$ & 18.851 & 266.3 & 9.846 & 0.000 & 2.375 & 5.875 \\
\hline K-E01 & 2 & 76.707 & 76.707 & 266.3 & 9.846 & 0.000 & 2.375 & 5.875 \\
\hline & 52 & 52.658 & 52.658 & 266.3 & 9.846 & 0.000 & 2.375 & 5.875 \\
\hline $\begin{array}{l}\mathrm{W}-\mathrm{P} 04 \\
\mathrm{~K}-\mathrm{O} 02\end{array}$ & 6 & 348.462 & 348.462 & 266.3 & $\begin{array}{r}9.040 \\
14.923\end{array}$ & 0.000 & 2.375 & 5.875 \\
\hline W-P05 & 56 & 18.850 & 18.850 & 266.3 & 9.846 & 0.000 & 2.375 & 5.875 \\
\hline K-E02 & 2 & $\begin{array}{l}10.0006 \\
76.706\end{array}$ & $\begin{array}{l}10.0006 \\
76.706\end{array}$ & 266.3 & $\begin{array}{l}7.040 \\
9.846\end{array}$ & 0.000 & 2.375 & 5.875 \\
\hline W-P06 & 52 & 52.657 & 52.657 & 266.3 & 9.846 & 0.000 & 2.375 & 5.875 \\
\hline K-X01 & 18 & 0.065 & 0.065 & 266.3 & 9.846 & 0.000 & 2.375 & 5.875 \\
\hline K-R01 (D/S) & 18 & 0.015 & 0.015 & 266.3 & 9.846 & 0.000 & 4.500 & 5.875 \\
\hline W-P07 & $\begin{array}{l}68 \\
68\end{array}$ & 0.009 & 0.009 & 266.3 & 2.284 & 0.000 & 4.500 & 5.875 \\
\hline
\end{tabular}

Figure 10. Wear rate analysis results using CHECWORKS.

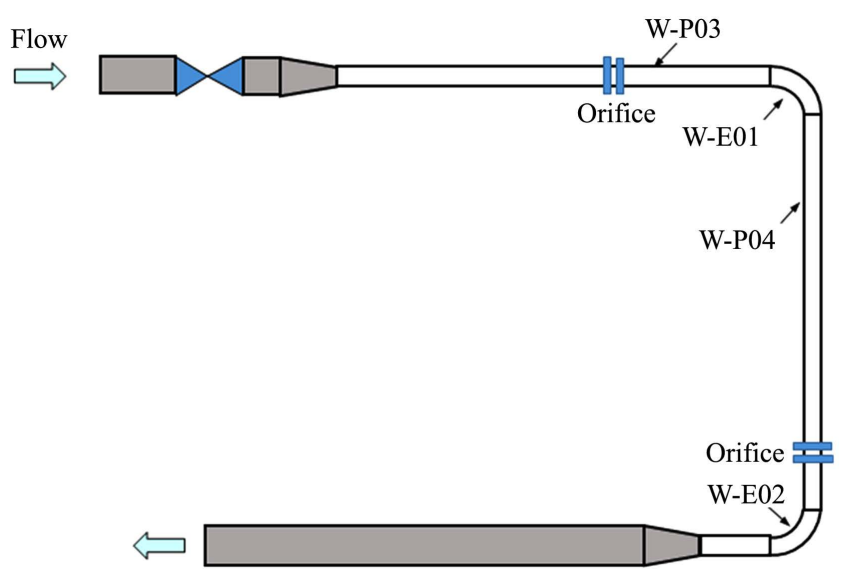

Figure 11. Comparison parts. 


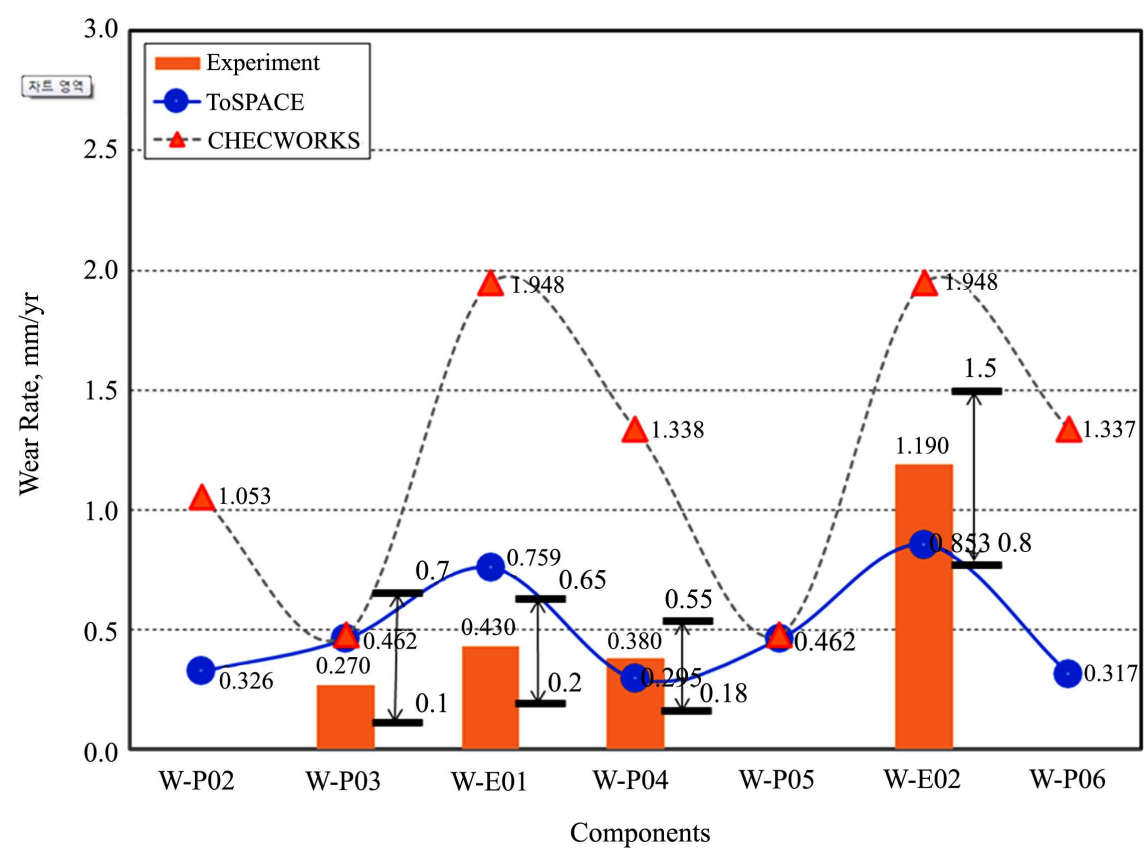

Figure 12. Comparison of wear rates derived from ToSPACE, CHECWORKS and experiment.

results. The dimension line on the right side of the bar graph shows the wall thinning rate distribution (maximum and minimum values) calculated from the whole point measuring the thickness in the experiment, and the bar graph is the mean thinning rate of the components.

CHECWORKS analysis shows that they are significantly larger than the experimental results and the ToSPACE analysis results. In CHECWORKS, the wear rates for W-E01 and W-E02 were calculated to be the same, and the wear rates of W-P04 and W-P06 at the downstream of elbow were calculated to be about the same. In W-P03 and W-P05, the wear rates were calculated almost similarly in ToSPACE and CHECWORKS. Most of all components fall under the outside value of the maximum and minimum ranges at the experiment except W-P03.

In ToSPACE, the ranking of components with highly calculated wear rates is $\mathrm{W}-\mathrm{E} 02>\mathrm{W}-\mathrm{E} 01>\mathrm{W}-\mathrm{P} 04>\mathrm{W}-\mathrm{P} 03$, and this trend was similar to the results of the FACTS experiments. In addition, it is estimated that the ToSPACE prediction results are within the range of the maximum and minimum values of the experimental results except $\mathrm{W}$-E01, so the prediction results are highly reliable. However, ToSPACE was found to highly reflect the effect of the turbulence at the downstream of the orifice in $\mathrm{W}$-E01, and the effect of the weak cavitation during the experiment affects the wall thinning in W-E02. So it is judged that the experimental value is somewhat higher than the predicted value.

\section{Conclusions}

Recently, KEPCO-E \& C has developed the ToSPACE program that can predict and manage pipe wall thinning on the secondary side of nuclear power plants. 
The program was developed from the demands of user's convenience at plant site. ToSPACE can build DBs at the same time as 3D construction, simultaneously perform the wall thinning analysis caused by FAC, LDIE, SPE, Cavitation, and Flashing, establish long-term inspection plan, analyze UT data reliability, and perform the UT data evaluation.

In this paper, the results predicted by ToSPACE were compared to the results of the experiments with the FACTS experimental facility and the results predicted by CHECWORKS to verify the accuracy of the FAC prediction that occurs most frequently in the secondary side piping of nuclear power plants. The wear rates were compared for the four components made of carbon steel including two elbows and two orifice downstream pipes.

The prediction results by CHECWORKS were generally much higher than those of experiments and the prediction by ToSPACE. Also, CHECWORKS calculations do not seem to fully take into account the combination effect of the piping components such as elbow or orifice. On the other hand, the results of ToSPACE show that the wear trends of the components are similar to the experimental results, and the wear rates calculated from the three components exist between the maximum and minimum values of the experiments. For this reason, the FAC prediction result by ToSPACE has been proven to have sufficient reliability. In addition, since ToSPACE has been developed for the convenience of site engineers in carrying out pipe wall thinning management work, it is believed that the use of ToSPACE at plant sites will maximize the efficiency of the work and contribute greatly to enhancing the integrity of pipes and the safety of NPPs.

\section{Conflicts of Interest}

The authors declare no conflicts of interest regarding the publication of this paper.

\section{References}

[1] EPRI (2004) Recommendations for Controlling Cavitation, Flashing, Liquid Droplet Impingement, and Solid Particle Erosion in Nuclear Power Plant Piping Systems. TR-1011231.

[2] NRC (1987) Thinning of Pipe Walls in Nuclear Power Plants. Bulletin 87-01.

[3] NISA/METI Press Release (2004) Automatic Shutdown of Unit 3 - 4th Report. Maeda and Amano.

[4] Hwang, K.M., Yun, H., Seo, H.K., Lee, G.Y. and Kim, K.W. (2019) Development of ToSPACE for Pipe Wall Thinning Management in Nuclear Power Plants. World Journal of Nuclear Science and Technology, 9, 1-15. https://doi.org/10.4236/wjnst.2019.91001

[5] KAERI (2018) Pipeline FAC Evaluation Technology Using Asymmetric Flow Analysis. Technical Report, KAERI/TR-7513/2018.

[6] Lee, J.Y., Lee, E.H., Kim, K.M., Oh, S.B., Cheong, Y.M. and Kim, D.J. (2019) Evaluation of the Effect of Asymmetric Flow on Pipe Thinning. The Korean Nuclear Society Spring Meeting, Jeju, 23-24 May 2019.

[7] Hwang, K.M., Yun, H. and Seo, H.K. (2018) Comparison of Wall Thinning Analysis 
Results between CHECWORKS and ToSPACE. Corrosion Science and Technology, 17, 317-323.

[8] EPRI (2009) CHECWORKS Steam/Feedwater Application Guidelines for Plant Modeling and Evaluation of Component Inspection Data. TR-1019176.

[9] EPRI (2012) CHECWORKS Steam/Feedwater Application (SFA). Version 4.0, Software Manual, TR-1025251. 